\title{
SVN Vascular \\ Endovascular treatment of patients with high-risk symptomatic intracranial vertebrobasilar stenoses: long - term outcomes
}

\author{
Tanja Djurdjevic, ${ }^{1,2}$ André Cunha, ${ }^{3,4}$ Ursula Schulz, ${ }^{4}$ Dennis Briley, ${ }^{4,5}$ \\ Peter Rothwell, ${ }^{4}$ Wilhelm Küker (1) ${ }^{2,4}$
}

To cite: Djurdjevic T, Cunha A, Schulz U, et al. Endovascular treatment of patients with highrisk symptomatic intracranial vertebrobasilar stenoses: long - term outcomes. Stroke and Vascular Neurology 2019;4: e000230. doi:10.1136/svn2019-000230

Received 13 January 2019 Revised 23 March 2019 Accepted 30 April 2019 Published Online First 2 June 2019
Dheck for updates

(C) Author(s) (or their employer(s)) 2019. Re-use permitted under CC BY-NC. No commercial re-use. See rights and permissions. Published by BMJ.

${ }^{1}$ Neuroradiology, Medical University of Innsbruck, Innsbruck, Austria

${ }^{2}$ Department of Neuroradiology, Oxford University Hospitals NHS Foundation Trust, Oxford, UK ${ }^{3}$ Department of Neuroradiology, Centro Hospitalar Gaia/Espinho, Vila Nova de Gaia, Portugal ${ }^{4}$ Department of Clinical Neurosciences, University of Oxford, Oxford, UK

${ }^{5}$ Neurology, Stoke Mandeville Hospital, Aylesbury, Buckinghamshire, UK

Correspondence to Dr Wilhelm Küker; wilhelm.kueker@ouh.nhs.uk

\section{ABSTRACT}

Background and purpose We present the long-term outcome after endovascular treatment of symptomatic intracranial posterior circulation stenoses.

Methods 30 patients with symptomatic intracranial posterior circulation stenoses exceeding $70 \%$ underwent endovascular treatment between 2006 and 2012. Data regarding presentation, follow-up, procedure details, complications and imaging follow-up were reviewed. All surviving patients underwent a phone interview to establish their current Modified Ranking Scales (MRS). Results Stenoses of the intracranial vertebral artery (24 patients) and basilar artery (6 patients) were treated with stents (10 patients), angioplasty alone (13 patients) or both (5 patients). Two procedures failed. One patient (3.3\%) died after the procedure, two had stroke $(6.6 \%)$ and one a subarachnoid haemorrhage without ensuing deficit. Two patients (6.7\%) had asymptomatic complications (dissection and pseudoaneurysm). The median clinical follow-up time was 7 years. Of the 29 patients who survived the procedure, 6 died due to unrelated causes. Three patients (10\%) had recurrent strokes and two $(6.7 \%)$ a transient ischaemic attack in the posterior circulation. Two patients had subsequent middle cerebral artery strokes. Five (16.7\%) patients had recurrent stenoses and three $(10 \%)$ occlusions of the treated artery. Retreatment was performed in six patients, three $(10 \%)$ with PTA and three $(10 \%)$ with stenting. Current MRS scores were as follows: nine MRS 0, eight MRS 1, four MRS 2 and one MRS 4.

Conclusions Long-term follow-up after endovascular treatment of high-risk symptomatic intracranial posterior circulation stenoses shows few stroke recurrences. Treatment of intracranial vertebral artery stenosis may be beneficial in appropriately selected patients.

\section{INTRODUCTION}

Posterior circulation events account for $20 \%$ of all ischaemic strokes. ${ }^{1}$ Underlying atherosclerotic large vessel stenoses are found more frequently than in the anterior circulation and contribute to the high risk of early stroke recurrence. $^{2}$ Endarterectomy $^{3}$ and carotid artery stenting ${ }^{4}$ have been proven to significantly decrease stroke recurrence in the extracranial internal carotid artery (ICA).
In contrast, case series suggest a high endovascular treatment risk for intracranial vertebrobasilar stenoses $(7 \%-10 \%$ stroke or death).$^{5}$ Randomised trials to date do not justify endovascular treatment but support the use of best medical management (BMT) alone ${ }^{6-8}$ However, all previous trials pooled patients with intracranial and extracranial vertebrobasilar stenoses, ${ }^{9}{ }^{10}$ although the underlying risks for these groups differ significantly. ${ }^{258}$ While the procedural risk for intracranial posterior circulation stenoses is higher than for extracranial lesions, so is the 90-day risk of recurrent stroke on medical treatment alone (33\% intracranial vs $16 \%$ extracranial). ${ }^{2}$

Previous trials reported few patients with intracranial posterior circulation stenoses, ${ }^{9}{ }^{10}$ and long-term outcome data are scarce. There is a particular lack of outcome data for patients suspected to have the highest stroke risk on BMT (ie, recurrent ischaemic events, occluded contralateral vertebral artery and poor collateralisation).

The aim of this study was to determine the long-term outcome of a particularly 'highrisk' subset of patients with symptomatic posterior circulation intracranial stenoses after treatment with stenting and/or angioplasty. The data were collected from patients treated before the initiation of a randomised trial into which all subsequent patients were enrolled.

\section{METHODS}

Patients, treatment policy and data collection This retrospective, single-centre study was performed as part of an authorised institutional audit against national guidance (Interventional procedure guidance 429). Included were all patients with symptomatic intracranial vertebral or basilar artery stenoses treated endovascularly between 1 January 2006 and 3 February 2012. Patients were selected for 
invasive treatment in an interdisciplinary meeting and remained under the care of stroke neurologists. All patients had $\geq 70 \%$ symptomatic stenoses deemed to be at high risk of recurrent ischaemic events due to at least two of the following:

1. Occlusion or hypoplasia of the contralateral vertebral artery.

2. Posterior communicating arteries of a size unlikely to sufficiently collateralise the vertebral arteries.

3. Recurrent ischaemic events in the territory of the stenosed artery despite BMT.

Clinical data regarding presentation and follow-up were obtained from patients' notes. The National Institutes of Health Stroke Scale (NIHSS) score was estimated from the details of the neurological examination and classified into mild stroke (NIHSS 0-5), moderate stroke (NIHSS between 6 and 14) and severe stroke (NIHSS $>14$ ). Procedure details, complications and imaging follow-up were collected and assessed via the patients' notes and images.

All surviving patients also underwent a standardised phone interview to obtain information on vascular events during follow-up and to assess their current functional status.

\section{Procedures}

All procedures were performed under general anaesthesia. All patients commenced dual antiplatelet therapy ( $75 \mathrm{mg}$ of aspirin and $75 \mathrm{mg}$ of clopidogrel) at least 5 days before the procedure. The dual antiplatelet therapy was generally continued for 1 year postprocedure, after which one antiplatelet agent was stopped. Patients received a bolus of 5000 units of heparin during the procedure. Platelet function inhibition was not tested.

All procedures were performed by the same operator (WK). The choice of the procedure (stent or angioplasty) and the stent type was at the discretion of the operator. All stents and balloons were CE-marked for treatment of arterial stenoses. No protection system was used. Follow-up imaging was performed according to the clinician's discretion.

Descriptive statistical analyses were performed with SPSS Software V.24. Fisher's exact test was used to compare categorical variables. $\mathrm{P} \leq 0.05$ was considered statistically significant.

\section{RESULTS}

Between January 2006 and February 2012, 33 patients with symptomatic posterior circulation stenoses were treated at our institution. Three patients presented with proximal stenoses of the vertebral artery and were excluded from this analysis. The study population thus consisted of 30 patients, 6 women and 24 men, with a mean age of 68 . Table 1 shows the principal demographics, indications and outcomes of the procedures.

\section{Clinical presentations and conditions prior to procedures}

All patients presented with symptomatic high-grade $(\geq 70 \%)$ intracranial posterior circulation stenoses. Of
Table 1 Baseline characteristics of patients

\begin{tabular}{|c|c|c|}
\hline \multirow{2}{*}{$\begin{array}{l}\text { Baseline characteristics, } \\
\text { n (\%) }\end{array}$} & \multirow{2}{*}{$\begin{array}{l}\text { Basilar artery } \\
\mathrm{n}=6\end{array}$} & \multirow{2}{*}{$\begin{array}{l}\text { Vertebral artery } \\
\mathrm{n}=\mathbf{2 4}\end{array}$} \\
\hline & & \\
\hline Age & $67(59-73)$ & $68(33-85)$ \\
\hline Male sex & 5 (83.3) & $19(79.1)$ \\
\hline \multicolumn{3}{|l|}{ Indication } \\
\hline Stroke & 1 & 5 \\
\hline Recurrent TIAs & 3 & 14 \\
\hline Recurrent stroke & 2 & 5 \\
\hline \multicolumn{3}{|l|}{ Procedure type } \\
\hline Angioplasty & $4(75)$ & $11(41.6)$ \\
\hline Restenosis & 0 & 3 \\
\hline Recurrent TIA & 0 & 1 \\
\hline Recurrent stroke & 0 & 0 \\
\hline Clinical complications & 1 & 1 \\
\hline Stent & $2(25)$ & $11(50)$ \\
\hline Restenosis & 1 & 3 \\
\hline Recurrent TIA & 0 & 2 \\
\hline Recurrent stroke & 1 & 1 \\
\hline Clinical complications & 0 & 2 \\
\hline Failed & 0 & 2 \\
\hline Recurrent stroke & 0 & 1 \\
\hline \multicolumn{3}{|c|}{ Posterior communicating artery existing } \\
\hline Yes & $4(66.6)$ & $10(41.7)$ \\
\hline No & 2 (33.3) & $14(58.3)$ \\
\hline $\begin{array}{l}\text { Time from the first event } \\
\text { to procedure in days } \\
\text { (mean) }\end{array}$ & 58 & 114 \\
\hline $\begin{array}{l}\text { Time from most recent } \\
\text { event to procedure }\end{array}$ & 19 & 23 \\
\hline $\begin{array}{l}\text { Treatment within } 14 \text { days } \\
\text { of symptoms }\end{array}$ & $3(50)$ & $11(46)$ \\
\hline
\end{tabular}

TIA, transient ischaemic attack.

these patients, 16 were treated following recurrent transient ischaemic attacks (TIAs), all having previously experienced either a brainstem, cerebellar or occipital infarction, except for 1 patient with only recurrent TIAs. Seven patients were treated following recurrent infarctions of either the brainstem, cerebellum or thalamus or occipital hemispheres. One patient was treated following disseminated infarcts in the posterior circulation following a previous posterior circulation TIA. Five patients were treated after their first event but regarded as of high recurrence risk due to the anatomy. Of these, three patients had occipital infarctions and two patients had disseminated posterior circulation infarcts. One patient presented with subarachnoid haemorrhage due to a flow-related aneurysm of the posterior communicating artery. The neurological deficits as assessed by the NIHSS were mild in the majority of patients; three patients had 
moderate deficits, and in one of these patients this was due to the residuals of a previous middle cerebral artery infarction.

The mean time from the index event to the procedure was 102 days $(2-455)$. The majority $(18,60 \%)$ of patients were treated after a recurrent event despite BMT. Fourteen patients were treated in the first month after the index event, and of these eight experienced a recurrent event prior to treatment. The mean time from the most recent event to treatment was 39 days (2-160), and 14 patients were treated within 2 weeks of their most recent event.

Twenty-two patients (73.3\%) underwent multimodal imaging for assessment of the underlying vessel pathology. Eight patients (26.7\%) were investigated with one imaging modality. Magnetic resonance angiography (MRA) was used in 26 patients (86.7\%), DSA in 22 $(73.3 \%)$ and Computed tomography angiography (CTA) in $8(26.7 \%)$.

The size of the posterior communicating arteries was assessed with the best imaging available for this purpose:
Digital subtraction angiography (DSA) in 22 patients and CTA in 8 patients.

All patients treated for symptomatic intracranial stenoses of a vertebral artery showed concomitant significant changes in the contralateral vertebral artery. In 13 patients $(54 \%)$ the contralateral vertebral artery was occluded, in $3(12.5 \%)$ severely stenotic and in 7 (29\%) hypoplastic. In one patient, the contralateral vertebral artery ended as a posterior inferior cerebellar artery.

\section{Representative cases}

Case 1

An octogenarian patient presented with abrupt-onset unsteadiness and right-sided hearing loss. The patient had a background of diabetes, hypercholesterolaemia, hypertension and was a previous smoker. The initial scan showed an acute right cerebellar infarction and the patient was treated with aspirin (figure 1A). Shortly after the patient had a fall and presented 10 days later with loss of balance. A repeat MRI demonstrated new bilateral cerebellar infarctions, larger on the left, and a small subdural
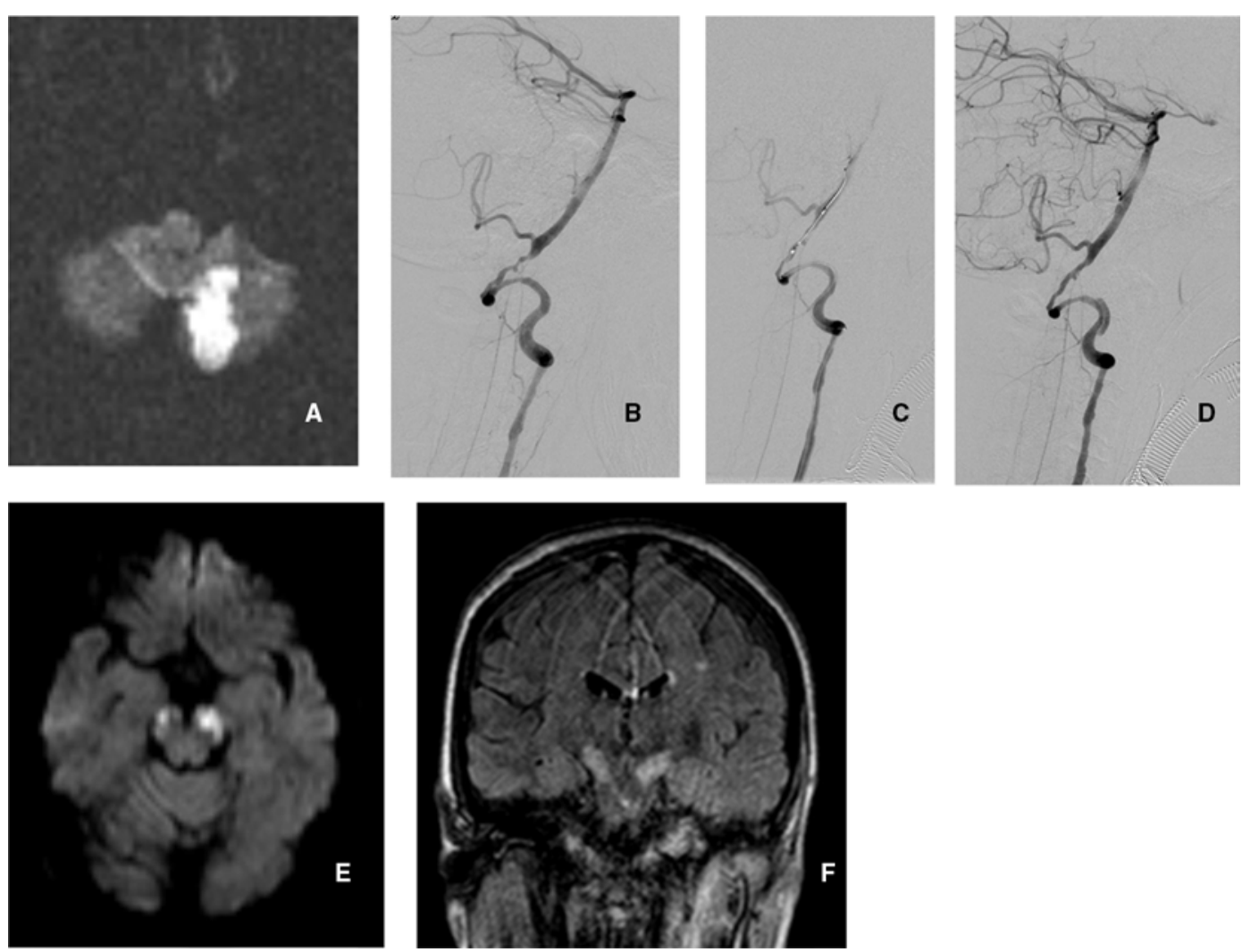

Figure 1 An octogenarian patient with repeated posterior circulation infarcts and systemic atherosclerosis. (A) The Diffusion weighted imaging (DWI) sequence confirms among others an acute left posterior inferior cerebellar artery (PICA) territory infarct. (B) The diagnostic angiogram confirms a high-grade stenosis of the left vertebral artery at the level of the dura perforation. The right vertebral artery is occluded. These changes were thought to be of atherosclerotic aetiology. The posterior communicating arteries are small. Note the origin of the anterior spinal artery immediately distal to the stenosis. (C) An angioplasty was performed with a Gateway $2.0 \times 15 \mathrm{~mm}$ balloon the following day under general anaesthesia. The image shows the balloon across the stenosis. Inflation time was $60 \mathrm{~s}$. (D) Postangioplasty there is better flow across the stenosis. There is some luminal irregularity but no intimal flap. The spinal artery remains patent. (E) The DWI MRI 2 days later shows new bilateral midbrain infarcts. (F) The coronal T2-weighted Fluid attenuated inversion recovery (FLAIR) sequence confirms the presence and locations of the new midbrain infarcts. 
haematoma. A contrast-enhanced MRA demonstrated an occluded left ICA and an occluded right vertebral artery, and the left vertebral appeared to have multifocal stenosis. The patient was then started on dual antiplatelet treatment and transferred to our centre. A diagnostic angiogram confirmed the MRA findings (figure 1B). The day following the cerebral angiogram, the patient had a further brainstem stroke. The patient then underwent an angioplasty (figure 1C,D). This was complicated by further midbrain and thalamic infarction (figure 1E,F) during a spell of low blood pressure the following night. The NIHSS score prestent was 6 , and poststent was 9 . The patient was discharged to rehabilitation and died 5 years later due to peripheral vascular disease (gangrene); there were no further strokes.

\section{Case 2}

A patient in the fourth decade of life presented with left facial weakness and right-sided sensory alterations (NIHSS score of 2). Imaging demonstrated occipital and brainstem infarction (figure 2A). Vascular imaging demonstrated an occluded left vertebral and a high-grade right vertebral stenosis (figure 2B,C). The patient was noted to be polycythaemic and had a background of hypertension and smoking. The patient was treated medically, including with phlebotomy. However, the patient had recurrent TIAs with headache, and visual and sensory symptoms. An angioplasty of the right vertebral was performed. The symptoms subsequently settled, but then recurred over the next 2 years. An angiogram demonstrated restenosis of the right vertebral. The patient then underwent a right vertebral artery stent (figure 2D,E). A follow-up angiogram 2 years later showed no restenosis (figure 2F). There were no further events, now 8 years following the index event. The patient has subsequently been diagnosed with diabetes.

\section{Procedures and complications}

Stenoses of the intracranial vertebral artery were treated in 24 patients $(80 \%)$, and stenoses of the basilar artery in $6(20 \%)$. No significant differences in complications, technical success, restenosis and outcome were found between these two groups. The left vertebral artery was more frequently affected (13 vs 11).
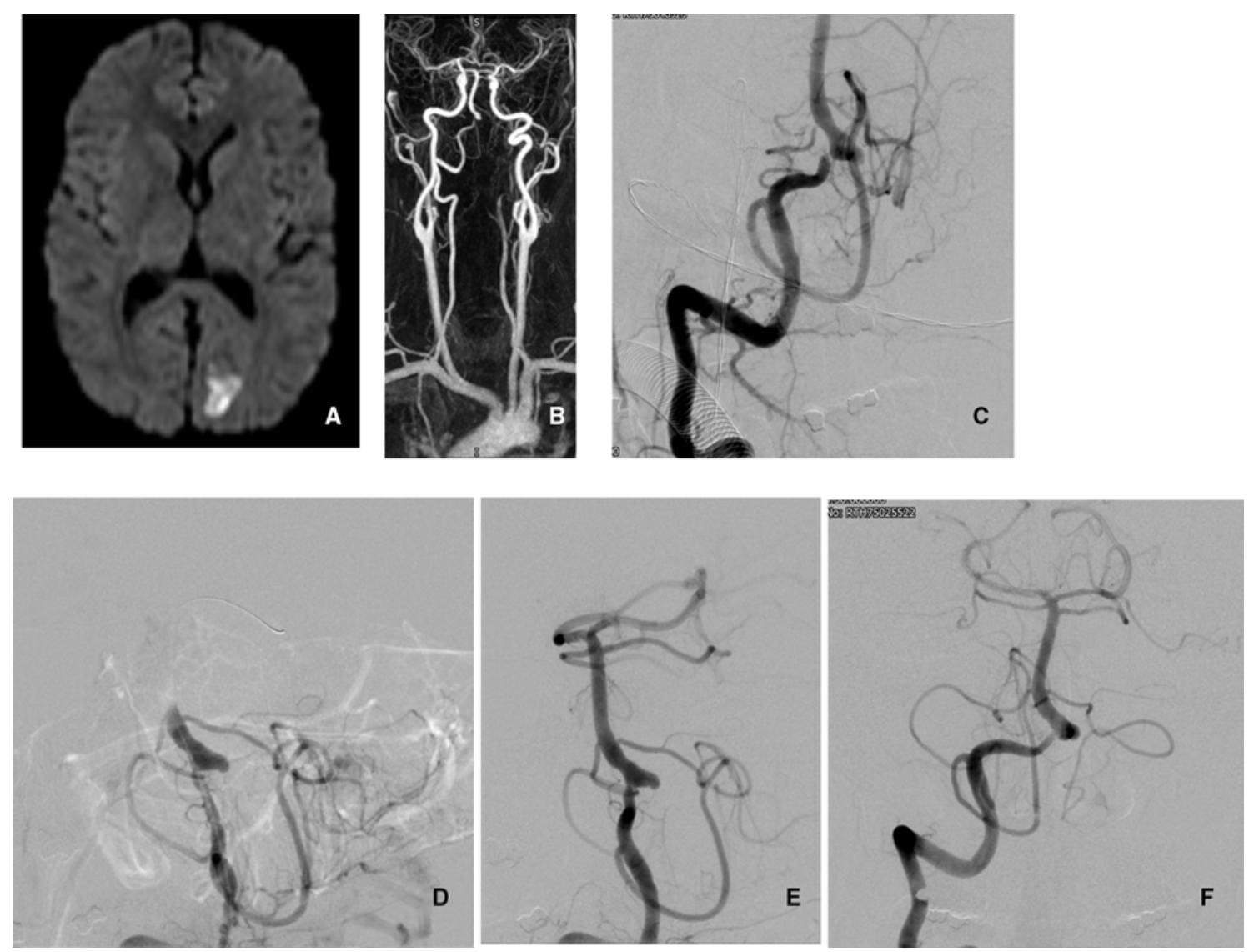

Figure 2 A patient in the fourth decade of life with recurrent posterior circulation events. (A) The diffusion weighted MRI shows an acute posterior cerebral artery (PCA) territory infarct. (B) The contrast magentic resonance angiography (MRA) confirms the occlusion of the left vertebral artery and the high-grade stenosis of the distal right vertebral artery. (C) The diagnostic angiogram under general anaesthesiashows the short but very severe stenosis of the right vertebral artery immediately before joining the basilar artery. (D) The stenosis was initially treated with angioplasty but symptoms recurred. Therefore, a drug-eluting coronary stent (Promus Element $2.25 \times 8 \mathrm{~mm}$ ) was deployed 18 months later. This image shows the stent placed across the stenosis causing distortion of the anatomy. (E) The immediate result after stent placement is satisfactory. (F) The 2-year follow-up angiogram shows no restenosis. The patient has remained asymptomatic for 8 years. 
Ten patients $(33.3 \%)$ were treated with a stent, 13 $(43.3 \%)$ with angioplasty and $5(16.7 \%)$ with a combination of both. In two patients $(6.7 \%)$ access to the stenosis failed without procedure-related complications. Of these two patients, one died 9 months later of non-strokerelated morbidity. The second patient sustained a further posterior circulation stroke 10 months later and then further carotid distribution infarctions.

One patient $(3.3 \%)$ died after a procedural basilar artery rupture. ${ }^{11}$ Two patients with prior stroke had strokes within 24 hours of the procedure, with NIHSS scores ranging from 7 to 11 preprocedure and an NIHSS score 6 after treatment.

One patient suffered a guidewire vessel perforation during the attempted treatment of a vertebral artery stenosis, from which he recovered without attributable deficit in spite of being on dual antiplatelet medication. In the treated vessel sections, no perforator territory infarct was encountered.

Two patients $(6.7 \%)$ had asymptomatic complications (dissection and pseudoaneurysm of the treated vertebral arteries).

Figure 3 shows the Kaplan-Meier curves showing 10-year survival free of risk of death, recurrent posterior stroke, or any recurrent posterior stroke or TIA.

A self-expanding stent (Wingspan) was used in two patients. Otherwise, various balloon-mounted and drugeluting coronary stents were deployed (Pharos, Taxus, Promus Element and Xience). Gateway or Maverick balloons were used for angioplasty. There was no significant correlation between the type of procedure or type of stent and vessel patency $(\mathrm{p}=0.59)$, outcome $(\mathrm{p}=0.4)$, complication rate $(\mathrm{p}=0.34)$, or stroke or death within 30 days postprocedure $(\mathrm{p}=0.48)$.

\section{Postdischarge follow-up}

The median clinical follow-up time was 7 years (range 1-11). Of the 30 patients, 7 died, including 1 who died from the procedure. One patient died of pneumonia 10 months after the procedure. Three patients died from various malignancies. Two patients died from vascular events, one due to gangrene 5 years later and the second from an intracerebral haemorrhage 9 years later.

Twenty-three patients are still alive. No patients were lost to follow-up (table 1). Three patients (10\%) had further posterior circulation strokes and two patients $(6.7 \%)$ a TIA during follow-up. Of these three patients with recurrent strokes, one was in a patient in whom the attempted treatment failed; this patient later also had a right middle cerebral artery infarction. In the second patient, recurrent stroke occurred at 6 months after discontinuation of dual antiplatelet therapy (remaining on a single antiplatelet); following this event all patients were treated with dual antiplatelet treatment for a minimum of 1 year. The third patient had a recurrent stroke 2 months after treatment. Of the TIA recurrences, one is described in the case report above, and the second occurred 2 years following vertebral artery stenting that
A

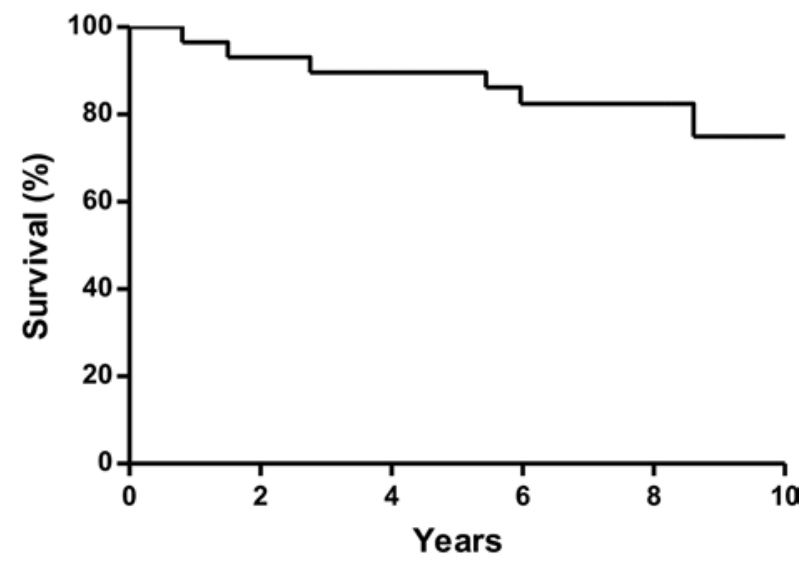

B

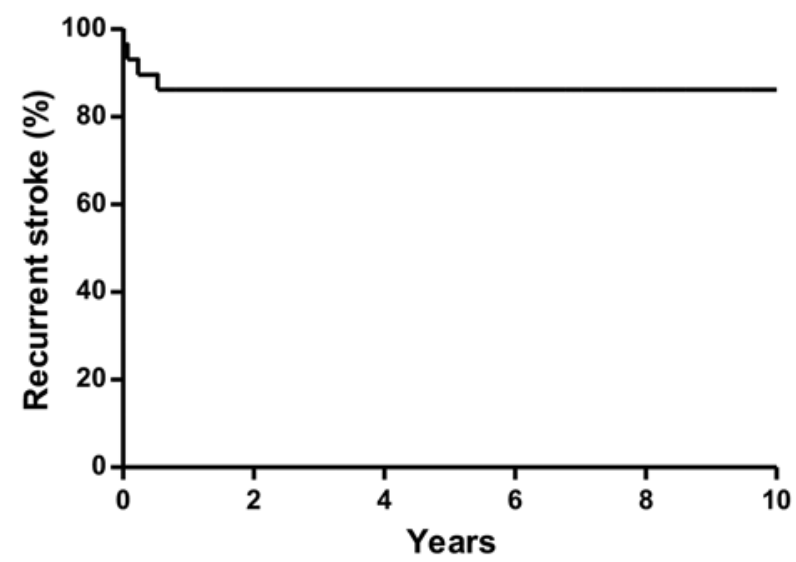

C

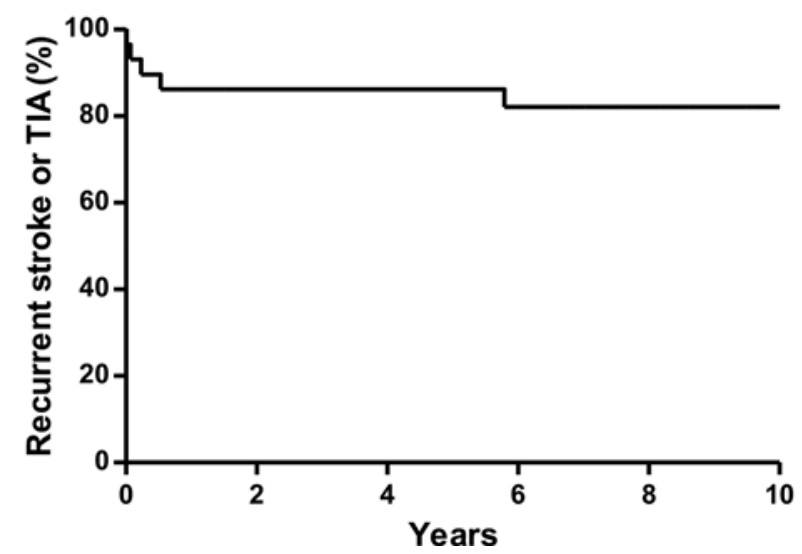

Figure 3 Kaplan-Meier curves of the 10-year risk of death, recurrent posterior stroke, or any recurrent posterior stroke or transient ischaemic attack (TIA). (A) Death, (B) recurrent stroke of the posterior circulation, and $(C)$ any recurrent stroke or TIA of the posterior circulation.

had been complicated by infarction; the patient was not considered well enough to undergo further intervention. He has been free of further cerebrovascular events since, although he has had myocardial ischaemia. A further patient had a new infarction in the posterior circulation on imaging but no clinical correlate. In addition, two patients experienced strokes in the distribution of the right middle cerebral artery. 
The Modified Rankin Scales (MRS) obtained during the telephone interviews were as follows: nine patients had MRS 0, eight had MRS 1, four had MRS 2, no patient had MRS 3 and one had MRS 4.

All but one patient was followed up with imaging. The median imaging follow-up time was 12 months (IQR 3.6-36). Nine patients had multimodal follow-up, while 17 underwent only one study. Twenty-two patients were imaged with MRA and 12 underwent DSA.

The last follow-up study did not show a stenosis in 19 (63\%) patients. Recurrent stenoses were found in five patients $(16.7 \%)$, and in three $(10 \%)$ an occlusion of the treated artery had occurred. Retreatment was performed in six patients, all with recurrent vertebral artery stenosis, two of whom were symptomatic and the other four patients were treated for recurrent asymptomatic stenoses.

Three patients $(10 \%)$ previously treated with stenting underwent Percutaneous Transluminal Angioplasty (PTA), and the other three (10\%), previously treated with PTA, had a stent inserted.

\section{DISCUSSION}

Recent randomised trials such as SAMMPRIS ${ }^{6}$ and VIST $^{1}$ do not support endovascular treatment of intracranial atherosclerotic stenoses, a procedure that is now rarely performed given its substantial procedural risk. For the majority of patients, 'best medical treatment' is undoubtedly the best treatment option. However, it is less clear if this applies to all patients or if there is a small subgroup with particular risk factors who may benefit from an interventional procedure (or further, more focused trials).

We therefore reviewed clinical and imaging outcomes of patients treated before the initiation of a prospective trial (VIST), into which all subsequent patients were enrolled and of which we were a main contributor. Hence, this is the first report of long-term outcomes after endovascular treatment of 'high-risk', symptomatic, intracranial, posterior circulation stenoses.

Over a median follow-up time of 7 years, recurrent posterior circulation strokes occurred in $10 \%$ of patients and none of these were fatal. One patient died of stroke in another territory and five patients succumbed to other causes. In comparison, the VAST and VIST trials reported stroke recurrence rates of $12 \%$ and $8.2 \%$ during follow-up of 3 and 3.5 years, respectively. ${ }^{9}{ }^{10}$ However, in both trials intracranial and extracranial vertebrobasilar stenoses were pooled.

Observational data indicate intracranial stenoses bear a higher risk of recurrent stroke. ${ }^{2}$ In the SAMMPRIS trial, the risk of recurrent stroke for intracranial vertebral stenoses after treatment was $21.1 \%$ over 2 years. ${ }^{12}$ In comparison, the long-term stroke recurrence after carotid stenting is around 7\%. ${ }^{13}$ Overall treatment numbers for intracranial posterior circulation stenosis were low in all trials: VAST 9 (of 57) patients, ${ }^{9}$ VIST 13 (of 61) patients ${ }^{10}$ and SAMMPRIS 36 patients. ${ }^{6}$
The precise natural history of untreated posterior circulation stenoses is uncertain. Literature suggests an early recurrence rate of ischaemic events of up to $30 \%{ }^{14}$ Data from SAMMPRIS suggest a particularly high risk of recurrence $(37 \%)$ in patients without an effective collateral circulation. ${ }^{15}$ A relatively high periprocedural risk may therefore be justified for an effective treatment.

Our procedural rate of major complications was 13\% (one death and three strokes), which is comparable with previous trials $(11 \%-22 \%) .{ }^{56916}$ The SAMMPRIS trial did not stratify procedural risk according to the exact location of the intracranial stenoses, while the VAST and VIST trials did not stratify risk according to intracranial or extracranial location of the posterior circulation stenoses. The relatively low complication rate in our series may be due to technical and training factors. While in SAMMPRIS only the Wingspan stent was used, our patients were mainly treated with balloon-mounted coronary stents (drug or non-drugeluting) or balloons. Moreover, all procedures were performed by the same operator. Recurrent stenoses or occlusions were seen in $26.7 \%$ (restenosis $16.7 \%$, occlusion $10 \%$ ) of the patients. This was similar to previous studies. $^{2}$

No significant difference in the patency rates between different stent types was observed. However, the subgroups for different stent types (Wingspan, coronary non-drugeluting and coronary drug-eluting) were small.

The diversity of treatment and devices reflects the long interval of this audit. There were significant changes in the available equipment, from the initial off-label use of very rigid coronary stents to the later introduction of dedicated intracranial devices (Wingspan, Pharos). The decision to use a stent or balloon was based on the anatomy as balloons are easier to navigate in tortuous anatomy.

Overall, we found no difference in the restenosis rate between angioplasty alone and stenting. However, in a large meta-analysis of 69 studies, Siddiq et $\mathrm{l}^{17}$ found that angioplasty with stenting had advantages over angioplasty alone in the treatment of symptomatic intracranial stenosis regarding restenosis and 1-year stroke and death rates. No difference was found in complications rates between the groups. In a recent study, Gruber et $a l^{18}$ compared a dedicated intracranial stent (Wingspan) with the first drug-eluting balloon certificated for intracranial use (Neuro Elutax SV) and found that ischaemic re-events and restenoses were significantly lower in the drug-eluting balloon group. However, while this may herald a significant development, the numbers of patients were small.

In our cohort, the mean time delay from first event to treatment was 102 days (range from 2 to 455). Only 14 patients were treated within the first month after the index ischaemic event. The risk of recurrent stroke peaks shortly after the first event. ${ }^{2}$ Treatment within the first 2 weeks ${ }^{10}$ may significantly reduce recurrence rates. Hence, treatment timing in our cohort was far from optimal. 
The delay of endovascular treatment was partly caused by uncertainty, which prevented clinicians from referring patients with symptomatic stenoses for an invasive procedure. Angioplasty or stenting was performed only after failure of the conservative medical stroke therapy with persistent recurrence of symptoms and on the assumption of a major haemodynamic compromise.

This long-term follow-up report in one of the largest patient populations treated for intracranial vertebrobasilar stenoses shows stable treatment results, indicating that treatment of intracranial vertebral artery stenosis may be beneficial in appropriately selected patients. With the exception of lower procedural complication rates, the data of our retrospective cohort conform with the literature. The most significant limitation of this report is its single-centre, retrospective design. While the numbers we report are larger than other reports, the numbers are still small. An adequately powered randomised clinical trial is needed to determine whether interventional treatment of intracranial vertebrobasilar stenosis in high-risk patients is superior to best medical treatment alone.

\section{CONCLUSION}

Long-term follow-up of patients after endovascular treatment of symptomatic intracranial posterior circulation stenoses suggests low stroke recurrence rates. Treatment of intracranial vertebral artery stenosis may be beneficial in appropriately selected patients. An adequately powered randomised clinical trial is needed to determine whether interventional treatment of intracranial vertebrobasilar stenosis in high-risk patients is superior to best medical treatment alone.

Contributors TD: collection and analysis of data, drafting of the manuscript. AC: collection of data. US: collection and analysis of data, editing of the manuscript. DB: collection and analysis of data, editing of the manuscript. PR: analysis of data, editing of the manuscript. WK: design of the study, analysis of data, editing of the manuscript, guarantor of integrity of the study.

Funding WK is supported by the National Institute for Health Research (NIHR) Oxford Biomedical Research Centre (BRC).

Disclaimer The views expressed are those of the author(s) and not necessarily those of the NHS, the NIHR or the Department of Health.

Competing interests None declared.

Patient consent for publication Not required.

Ethics approval The study was approved by the institutional review board. Provenance and peer review Not commissioned; externally peer reviewed. Data sharing statement No additional data are available.

Open access This is an open access article distributed in accordance with the Creative Commons Attribution Non Commercial (CC BY-NC 4.0) license, which permits others to distribute, remix, adapt, build upon this work non-commercially, and license their derivative works on different terms, provided the original work is properly cited, appropriate credit is given, any changes made indicated, and the use is non-commercial. See: http://creativecommons.org/licenses/by-nc/4.0/.

ORCID iD

Wilhelm Küker http://orcid.org/0000-0002-1739-6115

\section{REFERENCES}

1. Markus HS, van der Worp HB, Rothwell PM. Posterior circulation ischaemic stroke and transient ischaemic attack: diagnosis, investigation, and secondary prevention. Lancet Neurol 2013;12:989-98.

2. Gulli G, Marquardt L, Rothwell PM, et al. Stroke risk after posterior circulation stroke/transient ischemic attack and its relationship to site of vertebrobasilar stenosis: pooled data analysis from prospective studies. Stroke 2013;44:598-604.

3. Rothwell PM, Eliasziw M, Gutnikov SA, et al. Analysis of pooled data from the randomised controlled trials of endarterectomy for symptomatic carotid stenosis. Lancet 2003;361:107-16.

4. Bonati LH, Lyrer P, Ederle J, et al. Percutaneous transluminal balloon angioplasty and stenting for carotid artery stenosis. Cochrane Database Syst Rev 2012;159:CD000515.

5. Eberhardt O, Naegele T, Raygrotzki S, et al. Stenting of vertebrobasilar arteries in symptomatic atherosclerotic disease and acute occlusion: case series and review of the literature. J Vasc Surg 2006;43:1145-54.

6. Chimowitz MI, Lynn MJ, Derdeyn CP, et al. Stenting versus aggressive medical therapy for intracranial arterial stenosis. $N$ Engl J Med 2011;365:993-1003.

7. Compter A, van der Worp HB, Schonewille WJ, et al. Stenting versus medical treatment in patients with symptomatic vertebral artery stenosis: a randomised open-label phase 2 trial. Lancet Neurol 2015;14:606-14.

8. Zaidat OO, Fitzsimmons BF, Woodward BK, et al. Effect of a balloon-expandable intracranial stent vs medical therapy on risk of stroke in patients with symptomatic intracranial stenosis: the VISSIT randomized clinical trial. JAMA 2015;313:1240-8.

9. Compter A, van der Hoeven EJ, van der Worp HB, et al. Vertebral artery stenosis in the basilar artery international cooperation study (BASICS): prevalence and outcome. J Neurol 2015;262:410-7.

10. Markus HS, Larsson SC, Kuker W, et al. Stenting for symptomatic vertebral artery stenosis: The vertebral artery ischaemia stenting trial. Neurology 2017;89:1229-36.

11. Gralla J, Rennie AT, Squire W, et al. Fatal hemorrhage after attempted treatment of a basilar artery stenosis. Case report. J Neurosurg 2009;111:102-4.

12. Lutsep HL, Lynn MJ, Cotsonis GA, et al. Does the stenting versus aggressive medical therapy trial support stenting for subgroups with intracranial stenosis? Stroke 2015;46:3282-4.

13. Brott TG, Howard G, Roubin GS, et al. Long-term results of stenting versus endarterectomy for carotid-artery stenosis. N Engl J Med 2016;374:1021-31.

14. Gulli G, Khan S, Markus HS. Vertebrobasilar stenosis predicts high early recurrent stroke risk in posterior circulation stroke and TIA. Stroke 2009;40:2732-7.

15. Wabnitz AM, Derdeyn CP, Fiorella DJ, et al. Hemodynamic markers in the anterior circulation as predictors of recurrent stroke in patients with intracranial stenosis. Stroke 2018;50. STROKEAHA118020840-147.

16. Stayman AN, Nogueira RG, Gupta R. A systematic review of stenting and angioplasty of symptomatic extracranial vertebral artery stenosis. Stroke 2011;42:2212-6.

17. Siddiq F, Memon MZ, Vazquez G, et al. Comparison between primary angioplasty and stent placement for symptomatic intracranial atherosclerotic disease: meta-analysis of case series. Neurosurgery 2009;65:1024-34.

18. Gruber P, Garcia-Esperon C, Berberat J, et al. Neuro Elutax SV drug-eluting balloon versus Wingspan stent system in symptomatic intracranial high-grade stenosis: a single-center experience. $J$ Neurointerv Surg 2018;10:e32. 